\title{
Innovative technologies for the formation and assessment of competencies and skills in the XXI century
}

\author{
Nadezhda Efremova ${ }^{1}{ }^{*}$, Olga Shapovalova ${ }^{1}$, and Anastasia Huseynova ${ }^{1}$ \\ ${ }^{1}$ Don State Technical University, Gagarin square, 1, Rostov-on-Don, 344003, Russia
}

\begin{abstract}
The paper classifies and generalizes innovative technologies for assessing the competencies and skills of the 21 st century students in the education system. Taking into account the requirements of the international academic community, criteria for assessing students' competencies in the context of the formation of functional literacy, the ability to study and evaluate independence, global competence and meta-subject skills (soft skills) are considered. The necessity of ensuring continuity of assessment of students' competencies at the levels of general and higher education, as well as the results of formative assessment as an integrative innovative educational technology for the formation, control and evaluation of educational achievements, is emphasized. The possibilities of formative assessment for the development of meta-subject competencies of students are considered. It contains information on the innovative EvidenceCentered Design competency assessment methodology, which contributes to the further development of control and evaluation activities to ensure reliable and valid assessment of students' achievements and quality assurance in a competency-based approach.
\end{abstract}

\section{Introduction}

Today, global changes are taking place around the world, including automation and robotization, digitalization and the formation of a network society, internationalization and integration, the ever-increasing rate of change in the environment and the socio-economic conditions of human life. The dynamic and fast-moving 21 st century puts forward new requirements for the results of training young personnel, requiring mobility, readiness for lifelong education, and the possession of universal practice-oriented competencies («soft skills») that allow one to independently master various types of professional activities. Accordingly, the need for pedagogical research on the development of integrated innovative methods and technologies for the formation and assessment of competencies and meta-subject skills that can increase the effectiveness of professional activity and enable the specialist to «switch» between industries while maintaining their relevance and competitiveness is growing. The new reality requires new approaches to education, new learning outcomes and new technologies for assessing students' achievements, the emphasis

\footnotetext{
* Corresponding author: nefremova61@donstu.ru
} 
is shifting towards the development of critical thinking skills, the ability to interact and communicate, and a creative approach to business [1,2].

In national education systems, increasing attention is paid to the need to form competencies and skills of the 21st century [3]. Many models of new learning outcomes are being built, in which the greatest attention is paid to the skills of self-education and selftraining, the formation of critical thinking, the development of curiosity and a creative approach to completing assignments. Particular attention is paid to the development of entrepreneurial ability, the ability to generate new ideas and translate them into projects. The value of such results is due to the fact that they allow the individual to better navigate in changing conditions, adapt to technologies, understand information flows, find their place and role in collaboration. The development of universal skills and competencies has become one of the leading trends that determine the educational situation and personnel policy of most countries.

What is so special about these new results from traditional results in the form of knowledge? First of all, their deep latency, interdisciplinary and meta-subject nature should be noted. Further, it is necessary to indicate their activity character, which leads to the fact that they are formed and evaluated only in the process of activity when solving educational or practical problems. Therefore, the forms of surveys, testing, tests and exams do not allow a reliable assessment of competencies and skills of the 21 st century, which require a higher and more complex level of assessment, including not only testing knowledge and skills, but also the ability to use them. When solving a specific complex task, solving a training or real problem, it is required to search for the missing knowledge, to work in a group. This requires basic skills: critical thinking, communication, creativity and the ability to creatively solve problems. They also distinguish between process evaluations and product evaluations, depending on whether it focuses on the stages of the activity performed or, independently of them, on the final result in the form of a product. This difference stems from the purpose of using the results of valuation and value judgments for conclusions and making management decisions.

In the educational system, there is always, and now especially, a great need for the most accurate determination of the latent characteristics of students, which include not only knowledge and skills, but also competencies and skills of the 21 st century. This is due to new requests of employers, the need to determine the quality of training and achievements of various educational organizations, create reliable feedback and sound management of the educational process. Evaluation of the development of the substantive aspects of the disciplines being studied is more or less reliable today, but as practice shows, there are great difficulties in assessing the competencies and skills of the 21 st century. Therefore, most often, an assessment of the knowledge of individual topics and sections is issued as an assessment of new learning outcomes.

The purpose of this paper is to systematize innovative approaches to authentic assessment of «soft learning» results.

\section{Results}

Patrick Griffin (Griffin Patrick, 2003) believes that a reliable assessment of competencies creates the conditions for providing feedback between learning outcomes and educational process technologies, student achievement and learning management policies [4]. At the same time, during the assessment process, it becomes possible to detect the problem of organizing and conducting the training process. This gives teachers the basis for correction and sound management of the educational process, and for students the development of self-esteem and increased motivation for self-learning. In combination with the conclusions of L. S. Vygotsky (1931), an authentic assessment makes it possible for everyone to see 
their own zone of proximal (nearest) development from the point of view of the achieved result and shows what needs to be worked on further. This ensures the formation of metasubject competencies, which determine the general educational actions and abilities of students.

One of the innovative methods for assessing skills and competencies is formative assessment. We conducted a pedagogical experiment in school practice to identify the benefits of formative assessment of meta-subject competencies through a network computer testing system based on the MyTest software package based on a regional innovative pilot site. In the experimental groups, the technology of formative assessment was used as a tool for the development of meta-subject competencies (the natural science aspect of functional literacy), while in the control groups, training was based on traditional didactic techniques. For the formation and assessment of meta-subject competencies, comprehensive assessment tasks based on a cross-subject basis based on the material of three academic disciplines biology, physics and chemistry - were used. Evaluation tasks (including tasks of a project nature) are aimed at developing the skills to work with information, the formation of semantic reading skills, and the use of computational skills. The key principles of NBIC convergence as a combination and synergistic enhancement of the achievements of nano-, bio-, informational and cognitive educational technologies became the methodological foundation.

A questionnaire survey showed that so far, teachers in Rostov-on-Don schools are not very familiar with both the technology of formative assessment and the possibilities of digitalizing assessment procedures. There is still no proper use of electronic diaries, the use of Web 2.0 technologies, and the possibility of cumulative assessment based on e-Portfolio to monitor the development of universal educational activities using students' mobile devices. In real pedagogical practice, formative assessment as an educational strategy is used only by $32,7 \%$ of 99 teachers of the natural science cycle and $22 \%$ of the humanitarian cycle [5].

The final results of the experimental and control groups (CG and EG) at the end of the school year were evaluated using the MyTest software network complex, which has a deep analytics module. This made it possible to integrate the results, as well as to reveal the level of mastering of individual educational topics or sections of the curriculum in various groups and subject areas. So, in the process of studying the discipline «Biology», a number of «sunken» topics were identified: «The integrity of the human body is the basis of its life» (Grade 8), «Biocenosis. Ecosystem» (Grade 9), which allowed us to make timely adjustments to the development of program sections through the use of formative assessment strategies. The result of the adjustment of the methodological work on the subject was a more intensive formation of subject and meta-subject competencies of students (self-assessment and academic independence skills) in experimental groups (one class in each parallel in grades 8 and 9), which gave a higher final result compared to control groups . Three components of meta-subject learning outcomes of schoolchildren (cognitive skills and cognitive universal learning activities; information skills; academic self-study skills) were evaluated in experimental (112 people) and control (107 people) groups (Table 1).

Table 1. The results of the assessment of meta-subject competencies.

\begin{tabular}{|l|l|l|l|l|l|l|}
\hline $\begin{array}{l}\text { Meta- } \\
\text { objective } \\
\text { achievement } \\
\text { levels }\end{array}$ & \multicolumn{3}{|c|}{ Experimental group } & \multicolumn{3}{c|}{ Control group } \\
\cline { 2 - 7 } & before & after & $\begin{array}{l}\text { attitude after } \\
\text { / before }\end{array}$ & before & after & $\begin{array}{l}\text { attitude after } \\
\text { / before }\end{array}$ \\
\hline Low & $33 \%$ & $20.5 \%$ & 0.62 & $41.0 \%$ & $31.8 \%$ & 0.77 \\
\hline
\end{tabular}




\begin{tabular}{|l|c|c|l|c|l|l|}
\hline Middle & $50 \%$ & $59.0 \%$ & 1.17 & $44.0 \%$ & $52.3 \%$ & 1.19 \\
\hline Advanced & $16 \%$ & $17.0 \%$ & 1.05 & $7.5 \%$ & $9.4 \%$ & 1.25 \\
\hline High & $1 \%$ & $3.5 \%$ & 4.0 & $7.5 \%$ & $6.5 \%$ & 0.87 \\
\hline
\end{tabular}

The distribution of schoolchildren achievements by the levels of formation of metasubject learning outcomes at the beginning and at the end of the forming experiment is presented in Fig.1.

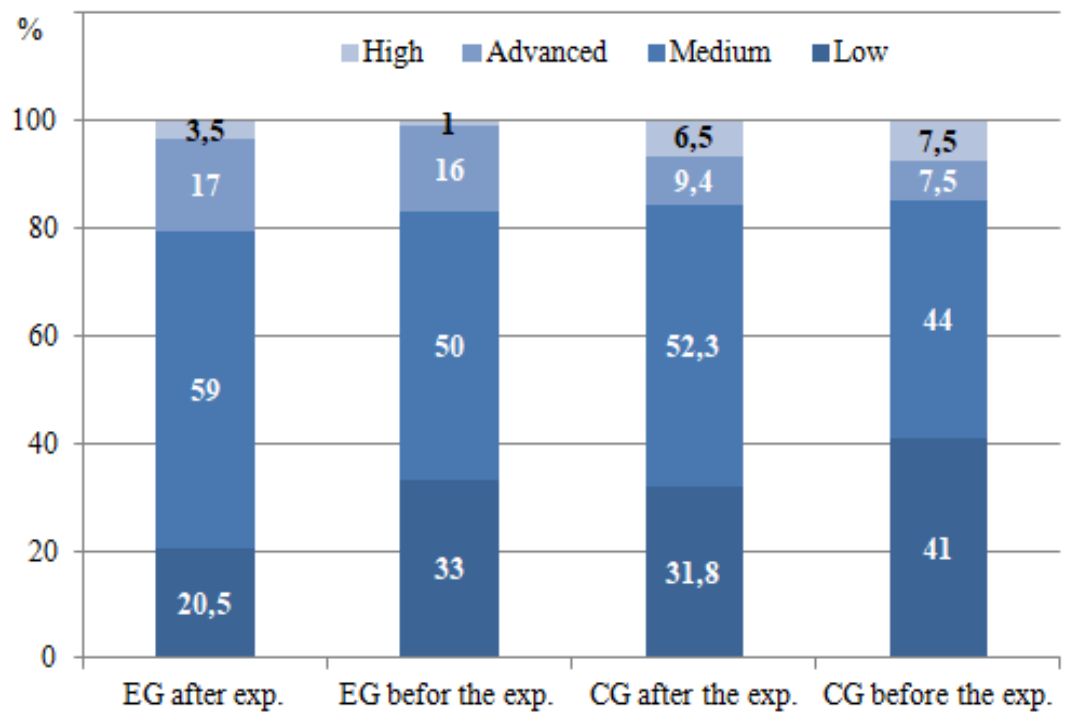

Fig. 1. Meta-subject learning outcomes of the experimental and control groups of schoolchildren

The validity of the results is statistically confirmed based on the Wilcoxon-MannWhitney method (the Pedagogical Statistics program was used for calculations). For the experimental group, the Mann-Whitney criteria Wamp. $=2.9868$ and Wcrit. $=1.96$. For the control group, Wemp. $=1.4153$ and Wcrit. $=1.96$. The significance of differences in these samples is $\mathrm{P}=95 \%$. Thus, it is possible to assert with sufficient confidence that the current formative assessment in the learning process is effective and gives a pronounced positive result of the formation of meta-subject achievements of students.

The interest in competencies at the international level is reflected in PISA comparative studies that go beyond the question posed by many assessment systems: "What did students learn?», The question « What can students do with what they learned?» comes to the fore.

Changing the requirements for general secondary education leads to a rethinking of the goals and objectives of vocational education. With what competencies do applicants come to universities, how to form, develop and evaluate students' competencies when they master basic educational programs?

Among a large number of assessment tools for competencies, the most frequently used are case studies and projects, monitoring activities, evaluating performance products, portfolios, etc. These assessment methods and tools help ensure that latent characteristics of students are manifested and their empirical referents are evaluated. Recently, the method of assessing the formation of competencies according to the Evidence-Centered Design (ECD) methodology [6] using pattern designs as reusable patterns for designing and developing means for assessing competencies and skills of the 21st century [7] has become widespread in international educational practice. ECD assessment models lead to substantiation of the reliability of competency assessment from the perspective of evidence-based reasoning [8, 
9]. A feature of the evidence-based argumentation methodology developed on the basis of pattern design is that it involves the formation of an assessment of the relative importance, usefulness, reliability, and conditions of the subject's activity in the application of the evaluation tool. The evidence-based ECD methodology includes the assembly of various training elements, statistical methods and expert analysis of arguments, rebuttals and evidence of student achievement and the quality of the evaluation tool itself.

In general, design patterns contain a number of required elements: name; scope and purpose; solved problem; general description of the participants; structure in the form of a diagram of the relationship between objects; conditions of sale; results; analysis of the consequences of the application; possibilities of application in other systems. The evidencebased project contains a series of procedures that focus on several issues. What can be observed in the subject's activity during the assignment, how can this provide evidence of the planned results, are the levels of student mastering the necessary knowledge, does he have the skills and abilities to be evaluated? How to select, structure and provide situations in order to provide opportunities for authentic assessment?

To address these issues, the key idea of ECD is to provide justification and evidence for the valuation argument through a series of steps. First of all, the definition and operationalization of the evaluated construct, the presentation of the evaluation arguments in a form convenient for processing. On the basis of the construct, the conceptual basis of the tool is being developed: the model of the test subject (assessed competencies, competency profiles, development levels, methods for describing levels in terms of descriptors); evidence models (selection of observed referents and variables, how to measure or evaluate them); assessment tool models (progress indicators). Next is the construction of a task with a set of specific tasks based on training or real situations that are interesting to solve; development of the design and specification of an assessment tool (which and how many tasks should be included in the task) It is necessary to prepare various instructions (in what form the learner gives an answer) and forms of results protocols. Finally, collecting evidence (a systematic process linking goals, objectives and data), conducting the assessment process and ensuring its representation, creating comfortable conditions for the subjects to interact with tools in the assessment situation; processing of results, evaluation of measured constructs, conclusions about the level of competencies, analysis of results and tasks, the availability of information. Thus, the model of student competencies, the model of collecting evidence (evidence), the model of the assessment tool and the development of its design, and the description of the scenario of the assessment process are consistently built in the ECD. Pattern design takes into account the main points of the assessment process: goals, design, administration forms, delivery of the task and its elements, a system for monitoring and evaluating the actions of the subjects, scaling of the results and their analysis, interpretation and report of evidence of the achieved learning outcomes and the quality of the model of the assessment tool.

A reliable assessment of achievements and their sound interpretation form the basis for the feedback between training, assessment, resources of the educational program and the development of further education policy (Fig. 2). 


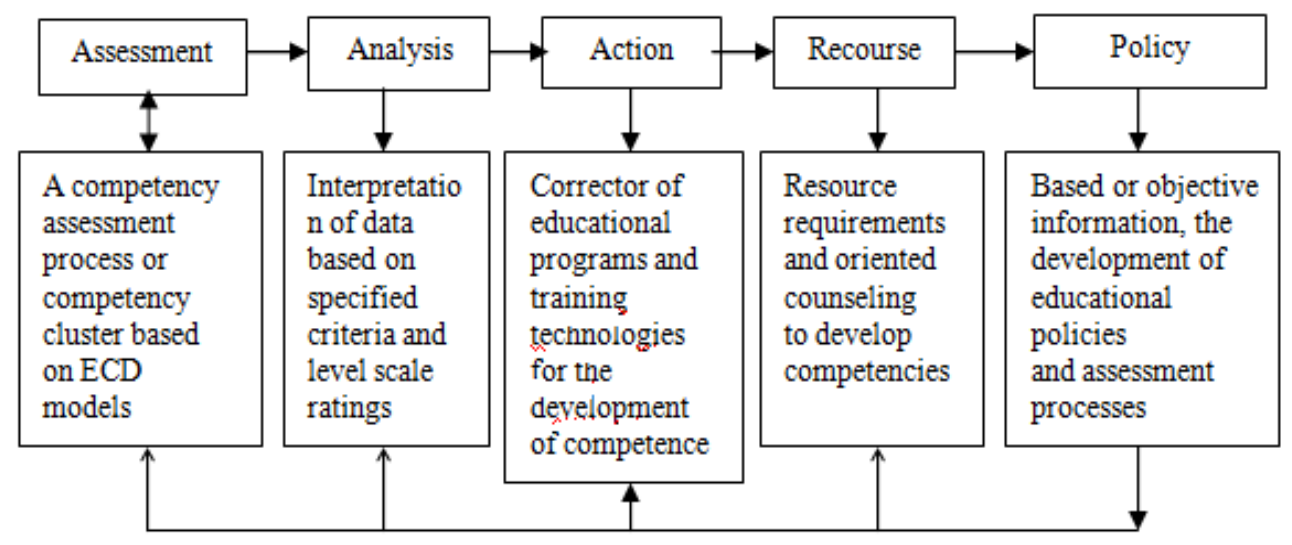

Fig. 2. A five-step approach to competency assessment.

For the formation of a comprehensive competency-based task, various sets of tasks are used. Among them may be tasks: with several options for solving them in the face of uncertainty, searching for information to write an essay on a given topic or preparing a presentation. There may be a topic for writing an article, a scenario for participating in a business game, solving cases, completing projects individually or solving complex problems in small groups, etc. The totality of points obtained in performing such tasks is displayed on a level scale, allowing you to determine the assessment of the formation of those declared in the construct competencies.

\section{Discussion}

The study of international experience in the use of formative assessment as an integrative educational technology for the formation and evaluation of meta-subject achievements of students, as well as the results obtained in the process of experimental work in a comprehensive school, indicate a pronounced effectiveness and great didactic potential of formative assessment. However, while in the domestic scientific literature there is a number of studies on the experience of testing and using this educational technology in the general education system, such experience with respect to the higher education system in Russian universities is still poorly covered. Meanwhile, Western researchers (Romero-Martín, 2017), (Hu Gallagher,), (Offerdahl, 2014) note the high effectiveness of formative assessment in the process of teaching general professional skills in the system of university education [10-12]. Formative assessment and assessment of competencies according to these studies [13-15] are tools for the development of critical and scientific thinking, a means of stimulating educational motivation, and contribute to the development of research competencies. Despite the fact that the introduction of formative assessment began at the end of the twentieth century, this pedagogical technology is still considered innovative. And forms and methods for assessing competencies and skills are under development. It seems to us promising the use of formative assessment in the process of developing students in general and vocational education, the organization of monitoring and evaluation of the universal and general professional competencies of future specialists, including more widely for assessing "soft skills" and competences of the 21 st century.

\section{Conclusions}


Summing up, we can say that the assessment process in its traditional form, in addition to recognized positive qualities, such as simplicity and universality, also has negative ones, such as a subjective factor and a formal attitude to assessment, both on the part of teachers and students, which is a factor in reducing educational motivation. Today, the use of alternative innovative technologies of pedagogical measurements of assessing educational achievements is an important aspect of modern control and evaluation activities, which helps to avoid or significantly reduce the negative effects of traditional forms and methods of assessment, which makes their application relevant and in demand. Of course, the construction of such forms of assessment is a laborious work that requires a certain preparedness of developers. However, the consistent use of innovative valuation technologies gives positive results, and repeated use compensates for the initial costs.

\section{References}

1. P. Griffin, Cambridge University Press, 21 (2014)

2. P. Luksha, Skolkovo. Olympus Business, 216 (2015)

3. R. Boyatzis, Articlein Journal of Management Development, 5-12 (2008) doi: 10.1108/02621710810840730

4. P. Griffin, B. McGaw, E. Care Springer, 362 (2015)

5. N. Efremova, O. Shapovalova, World of Science. Pedagogy and psychology, 6(7) (2019)

6. R. Mislevy, G. Haertel, M. Riconscente, Springer-Verlag GmbH, 123 (2017) doi: 10.1007/978-3-319-52246-3

7. E. Toulmin, Stephen Cambridge University Press, 259 (2003)

8. N. Efremova, EC Psychology and Psychiatry SI, 2, 1-4 (2020)

9. K. Ford, UMUC Center for Innovation In Learning and Student Success (CILSS), 22 (2014)

10. R. Romero-Martin, F.-J. Castejon-Oliva, V.-M. Lopez-Pastor, A. Fraile-Aranda Education Research Journal, 1-12 (2017) doi: 10.3916/C52-2017-07

11. Y. Hu, M. Gallagher, International Journal of Social Science and Humanity, 3(6), 553558 (2013) doi: 10.7763/IJSSH.2013.V3.302

12. E. Offerdahl, R. Montplaisir, Biochemistry and Molecular Biology Education, 29-38, 42(1) (2014) doi: 10.1002/bmb.20757

13. N. Efremova, Basic research, 1161-1166 (2014)

14. B. Dahal, Journal of Social Science Research, 75-93, 1(1) (2019) doi: 10.3126/sijssr.v1i1.26918

15. M. Higgins, F. Grant, P. Thompson, A. CEBE Innovative Project in Learning \& Teaching, 62 (2010) 